\title{
e-Diplomacy as Instrument for Establishment of Interethnic Relations
}

\author{
Liudmila Reshetnikova* \\ Volgograd State University, Department of international relations, political science and area study, 400062 Prospekt \\ Universitetskiy, 100, Volgograd, Russian Federation
}

\begin{abstract}
The article is devoted to e-diplomacy (also known as digital diplomacy) which is a component of public diplomacy. Digital diplomacy is a one of the new tools of foreign policy that is aimed to solve the problems of international and interethnic relations. The article examines the concept and definition of digital diplomacy that concentrates on the use of social networks and digital media in the field of foreign policy. Some risks and threats of e-diplomacy are also considered. The use of opportunities of information and communication technologies for solving the problems of foreign policy and influence on mass consciousness by means of the Internet, social networks is analyzed.
\end{abstract}

Public diplomacy has always been an important component of the foreign policy of the leading states of the world. Accelerating the processes of globalization, the intensive development of the Internet as a way of promoting ideas and their retransmission to society have helped to turn public diplomacy into one of the most important instruments of world politics. If the traditional public diplomacy as a way of influencing the public opinion of foreign countries included information propaganda, carried out mainly through radio, television and film production, the development of the Internet greatly expanded the role and possibilities of public diplomacy and created new ways of interaction not only between world leaders, but and with non-governmental organizations and individuals. A growing number of Internet users, discussing the most important social and political problems in social networks, have caused a change in the essence of modern public diplomacy. Public diplomacy programs of Western countries are transferred to cyberspace, and the key target audience is millions of citizens.

Today, e-diplomacy (also known as a digital diplomacy) is a part of public diplomacy that is the interaction of individual groups and the interests of one country and another; a report on international activities and its impact on politics, a dialogue between those whose task is to establish and maintain a dialogue, both diplomats and foreign correspondents; as well as the process of intercultural communication [1]. Digital diplomacy may be considered through the perspective of soft power, which Joseph Nye defined to mean the ability to set the agenda in world politics through persuasion, enticing and attracting others through the force of one's beliefs, values and ideas, and not through military or economic coercion [2]. Furthermore, in 2003
J. Nye identified three possible ways of influencing other actors: coercion and bribery, constituting "hard power", and using his attractiveness, that is, "soft power". The development of these concepts was the so-called "smart power" - an approach in which a combination of "hard" and "soft" force is used [3].

E-diplomacy also as an Internet diplomacy, net diplomacy, cyberdiplomacy, "public diplomacy Web 2.0" has started to develop on the basis of modern information and communication technologies. And it has been evolving into a true policy tool beyond the real of communications and public diplomacy.

Digital diplomacy based on the application of social networks to ensure the interaction of state diplomats with foreign Internet users. It should also be noted that social networks, whose users are increasingly have played an important role in mobilizing citizens and public opinion. A global net can not only serve democratization tool, but also contribute to the strengthening of authoritarian trends, which limit the freedom of citizens. Digital diplomacy is one of the directions of public diplomacy, oriented in involving in the diplomatic practice wide sections of the population. It is possible to say that any foreign policy activity in the Internet will be a digital diplomacy, but not everyone can be called "public diplomacy 2.0" (and only the one, which is associated with the application of technology Web 2.0) [4].

The term "e-diplomacy" was widely distributed with the release in the spring of 2012 of the paper of the Australian Lowy Institute's research fellow Fergus Hanson, invited to the American Brookings Institution, "Revolution@State: the spread of eDiplomacy". Six months later he published the second part of the study "Baked In and Wired: eDiplomacy@State". The researcher was the first to try to systematize the program

* Corresponding author: reshetnikova_lm@ volsu.ru 
work carried out by the State Department for several years, which is also called "digital diplomacy" - more precisely, "e-diplomacy". However, F. Hanson, having a significant baggage of positions and statements of representatives of the U.S. State Department on digital diplomacy, is forced to confine himself, as he puts it, to the "working definition" of the term: "the use of the world wide web and new information and communication technologies to assist in the implementation of foreign policy goals" [5].

The emerging information environment begins to dictate its rules games to state bodies engaged in the foreign policy. It complicates the international system, expands the list of its participants, changes the formats of socio-political events, directly costs the global configuration becomes a factor of instability and emergence of additional threats. It is not just an information component, but also the patterns of formation and flow of conflicts and other significant processes. The source of digital diplomacy is nongovernmental and network organizations that more effectively cover a certain part of the foreign audience with their influence. A platform for digital diplomacy is the Internet, where the news and music formats of radio and television programs are transferred, the image of the country or organization. Members of foreign nongovernmental organizations, Internet users and young people become the main targeted groups of digital diplomacy [6].

Modern diplomacy, in fact, is concerned with not only international problems, but also the root problems of the national life - from security in its modern, "global" pro-reading to life quality issues, including the preservation and creation of workers places. In the face of new challenges, the structures and methods of diplomacy have changed; new models are being proposed by integration diplomacy and paradiplomacy.

Digital technology is an important retranslator of ideas and in general contributes to democratization and spreading the power through the domestic and international policy. It is important to note the efficiency of using electronic resources for the implementation of digital diplomacy: when establishing contacts with online audience and the formation of new communication tools digital diplomacy can provide the ability to address directly to the target audience with specific messages, including cooperation of authoritative opinion-makers.

The directions of usual foreign policy institution's work maybe divided into three types: 1) intrasystem (accumulation, optimization of selection and distribution of estimates and proposals, management of huge flows of own information both within the agency and in the overall mechanism of foreign policy decisions); 2) external application (including public diplomacy) aimed at strengthening the position and reputation of the country abroad, the use of "external expertise" (expert communities, think-tanks, etc.) with the help of digital tools. 3) "mixed" (joining, where necessary, the functions of the first two types, for example, in the response and settlement of emergencies (which are not reducible to technological or natural disasters). It should be added that the coverage of e-diplomacy will obviously be wider than national boundaries. As new methods are developed by different states, especially those in allied relations, separate joint programs can be created to coordinate certain actions online [7].

It is quite possible to affirm that digital diplomacy is a foreign policy essential. The world is such that state and non-state entities all compete for influence and power in the same online space. That space now hosts more than 3 billion people, most of whom only access the internet through their cell phones. When used properly, digital diplomacy is a persuasive and timely supplement to traditional diplomacy that can help a country advance its foreign policy goals, extend international reach, and influence people who will never set foot in any of the world's embassies [8]. The advantage of social media provides the opportunity to reach citizens of other countries in near real-time. Social media platforms also provide spaces for interaction, increased engagement, and thus furthering the goals of diplomacy. The potential ease with which social media can be accessed and the low cost in comparison to other methods make it an attractive tool for many embassies, as well as other government offices that are facing budget cuts and demands to increase engagement [9]. Numerous platforms allow for the use of more dynamic content, such as videos, photos, and links, than traditional methods of giving lectures or passing out pamphlets. In addition, social media are key channels in reaching youth populations, a major goal of current public diplomacy efforts.

Digital technologies can be particularly useful in public diplomacy in the field of information collection and processing, in the field of consular activities, and for communications during emergencies and disasters. International practice shows that competent use of digital diplomacy tools can bring big dividends to those who invest in it. Moreover, digital diplomacy does not always require financial investments. On the contrary, it is often aimed at reducing costs. The human factor - the desire of employees to grow, master new technologies, spend part of their work time on working with the target Internet audience, processing electronic data, and creating information and reference materials - is very important [10].

Understanding the importance of such investments in e-diplomacy, some states started to use the world wide web, social internet media as strategic tools for its foreign policy. The United States was one of the first countries realized the importance of the Internet for promoting national interests abroad. Already since the 1990s the American government has aimed to appeal to a foreign Internet audience. Moreover in the 2000s U.S. Presidential elections and British domestic politics have both demonstrated the growing importance of being present on the Internet. Internet removes the barriers to providing information and participating in debates which existed through traditional media and networks. Some governments have sought to use this by launching online debates. The Internet is merely a new means of communication that reinforces trends that already existed. Global terrorism and NGOs were a major factor 
in international relations before the Internet, and though people can more easily participate in foreign policy debate, $80 \%$ still have little or no interest in doing so [11].

Indeed, the discussion of foreign policy and global problems at the level of not only diplomats, but also ordinary users of the Internet and mobile phones can help to strengthen international security through the formation of an atmosphere of trust in the international relations. In this context, digital diplomacy programs contribute to the formation of a single information space, a global of civil society, as well as the folding of the management system in the world politics and the resolution of crises and problems affecting all countries of the world. A wide spreading of social media platforms and new media and their usage by states should be seen as a source of new opportunities for the development and resolution of conflict situations. Indeed, discussions of the problems of the post-conflict at the level of ordinary Internet users and cell phones can help to strengthen the security of formation of an atmosphere of trust in international relations. In this context, e-diplomacy programs promote to formation of a single information space, civil society and the conflict resolutions, and to establish interethnic dialogue. For example, the creation of a social network of young leaders YaLa Young Leaders of the Middle East that includes Palestinians, and Israelis, which allows us to establish links and to establish mutual understanding "ahead of the curve", prevent a new round of the conflict cycle.[12] Due to its popularity, social media is widely use by the communities, as well as the individuals involved conflict and interested in its settlement and reduction of nonconsequences. This is an affordable tool that reduces costs of collective actions, which increases the effectiveness of coordination, not always promotes equally successful results, but widely is used and it is obvious that this trend will continue in the future.

Today e-diplomacy is able to play important role in interethnic relations, taking into account that such relations can be considered as the interaction of nations in different spheres: economy, politics, culture, social sphere. The most vividly interethnic relations are manifested in conflict situations that highlight all aspects and aspects of such relations. For the ethnic processes of modernity, two tendencies are typical: integration cooperation, the unification of different ethnic communities, the rapprochement of all aspects of the life of peoples. Interethnic relations can be friendly, mutually respectful or hostile. All this was reflected in digital diplomacy. Such tools of social media as Twitter or Instagram are completely satisfied with requirement and conditions of e-diplomacy implementation and facilitation of international, interethnic relations. For example, the Instagram account of the U.S. citizen Drew Kelly (instagram.com/drewkelly), who taught the English in the North Korea, demonstrates a cozy and pleasant view of the country without hostile intentions. The side of North Korea is also watching the aspirations to get to the digital diplomacy. DPRK's party twitter account has the American Jimmy Dushku (@JimmyDushku - “I'm the only person North Korea follows on Twitter") as follower, despite the often hostile rhetoric of the Koreans for the United Stated.

Since 2012 Twitter-diplomacy began to develop actively and it was named as "Twiplomacy". Twitter or Facebook remains only a part, but important, of the tools of e-diplomacy. In this regard, it is useful to note that the popularity of the topic of "diplomatic Twitter" received a significant push with the appearance of the article "EDiplomacy: foreign policy in 140 characters" [13]. In 2012 "E-Diplomacy Hub" was opened by France-Presse, where in real time the Twitter-activity of heads of states and representatives of foreign affairs agencies is summarized [14]. Moreover the company "BursonMarsteller" has started to study the development of "official Twitter" (using by Twitonomy). The company has issued annual global survey about twiplomacy. It also received large-scale coverage, and the new term "twiplomacy" began to supersede others already adopted within the framework of understanding "digital diplomacy". Even in spite of the fact that the authors of the material stipulate: "twiplomacy" is only the name of research on the use of Twitter by world leaders. Let us also note that some government officials in a number of countries even resort to Twitter instead of e-mail in their correspondence. Politicians and experts have already noticed some nuances in the use of Twitter. According to the authors of the Burson-Marsteller report, the U.S. president and his administration, for example, focused on domestic political issues and, accordingly, the American audience, including by virtue of the presidential election campaign.[15] And if earlier the establishment of relations between the leaders of states and high-ranking officials was mostly carried out with personal acquaintance at various events, then Twitter makes it possible to establish trusting relations on a "contactless" and permanent basis - with greater impact than from phone conversations.

It is possible to notice that digital diplomacy is a persuasive and timely supplement to traditional diplomacy that can help a country advance its foreign policy goals, extend international reach, and influence people who will never set foot in any of the world's embassies. The advantage of social media provides the opportunity to reach citizens of other countries in near real-time. Social media platforms also provide spaces for interaction, increased engagement, and thus furthering the goals of diplomacy. But despite this there are some specific challenges for the use of digital diplomacy.

With all the objective advantages of digital technology, policy, recognizing the importance of the Internet, considers the development of digital diplomacy exclusively in the context of risks and threats of cybercrime, hacking, cyber-terrorism. The Internet is perceived as a channel extremism and terrorism, the imposition of an alien ideology and external nonpolitical propaganda, as a means of information warfare. Acknowledgment of the fact that the programs of digital diplomacy are perceived as a threat on the international arena, is the current tendency to fragmentation of the global formational sphere, compute national and regional segments. The result of the violation of the balance of power is also the race weapons in the information 
sphere. Informatization generates new threats for the leading states, strengthening the asymmetric component of modern conflicts, as a result of which the technologically advanced states become vulnerable. The emergence of digital diplomacy should not be seen as a threat international security, but rather as a source of new opportunities for the development and resolution of contemporary global problems, the scale of which is not commensurate with the capabilities and resources of the one state. The global informational networks and social media offer opportunities for the global civil society and global debates. Public diplomacy in this context is not seen as a diplomacy of the state, but as people's diplomacy, which creates the basis for the national diplomacy and acts on top of the international relations based on common approaches.

Information about breaking international crises that once took hours or days for government officials and media to disseminate is now being relayed real-time to the world not only via radio and television, but over the Internet as well. Ironically though, for policy-makers, instant dissemination of information about events both far and near is proving to be as much a bane as a bounty. In other words, digital diplomacy has its risks, which include information leakage, hacking, and anonymity of Internet users. A good example of information leakage is the Wikileaks episode. "On the 28th of November 2010, pandemonium spread among foreign ministries throughout the world as WikiLeaks began publishing some 250,000 diplomatic cables sent between U.S. missions around the world and the State Department in Washington. These cables included frank assessments by U.S. diplomats of world leaders, governments and their host countries." Additionally, diplomatic rivals, including both state and non-state actors (such as terrorist organizations), may try to hack into government systems and extract information of use to themselves. Another challenge of digital diplomacy is the internet's "culture of anonymity" anyone can adopt any persona, address or even attack anyone. Anyone can mimic and pretend to be someone else, or actively seek to cause mischief. Interestingly also, sometimes, even digital diplomacy advocates and practitioners also commit blunders in their uses.[16] Also an obstacle to the development of digital diplomacy is the absence universally recognized criteria for assessing its effectiveness, low level of participation nongovernmental organizations in its implementation, as well as insufficient efforts foreign ministries of different countries to establish a dialogue with foreign audience.

It is also important to remind that digital diplomacy is not supposed to be an end in itself, but rather to serve clearly defined foreign policy objectives. The disruptive character of technological breakthroughs may lead, however, at least in the initial stage, to a decoupling of digital diplomacy from foreign policy. Quick adoption of digital tools without an overarching strategy of how they should be used in support of certain foreign policy objectives is likely to create problems of policy coordination and implementation. The risk for ministries of foreign affairs in this case is to find themselves consuming valuable resources on multiple mini digital campaigns with no clear direction or strategic compass to follow.[17]

In the information space, digital diplomacy can become a tool for promoting national interests in the world arena providing sufficient intellectual, technological and organizational resources. Digital diplomacy should be aimed to efficiency in the application of knowledge, accumulated in departments and government in general, so that this knowledge was accumulated and used properly to exchange them, and also optimally applied to ensure national interests abroad; maintaining public relations, inclusion of new communication tools for a thorough assessment of the key addresses to important segments of the influence on authoritative figures in the net; development of technologies and online modes and use of external expert resources in the implementation of state tasks; effective coordination and planning of foreign policy in government structures.

It should be concluded that lots of works of foreign ministries all over the world continue to be managed through the ordinary diplomacy: instructions to ambassadors and embassies in foreign states; meetings and negotiations that are not available to the public; collecting, reporting, and summarizing relevant information; formation and involvement of interested groups; the resolution of many technical problems by using intergovernmental tools like international conferences, international and regional organizations. Therefore, it is difficult to imagine that digital diplomacy will completely replace conventional diplomacy in its classical sense, but nevertheless, e-diplomacy as a special tool can strengthen the state in contemporary foreign policy and the relations among nations.

\section{References}

1. N. J. Cull, Public diplomacy: lessons from the Past. (Figueroa Press, L.A., 2009)

2. J.S. Nye, Foreign Policy 80, 170 (1990)

3. J.S. Nye, Foreign Affairs 4 (88), (2009)

4. A. Marchukov, Science Journal of Volgograd State University: History. Area Studies. International Relations 4 (28), 106 (2014)

5. F. Hanson, Foreign Policy at Brookings (2012) URL: https://www.brookings.edu/wpcontent/uploads/2016/06/baked-in-hansonf-5.pdf (date of access: 11.02.2018)

6. N. Tsvetkova, USA - Canada: economy, policy, culture 3, 110 (2011)

7. F. Hanson, Foreign Policy at Brookings (2012) URL: $\quad$ https://www.brookings.edu/wpcontent/uploads/2016/06/baked-in-hansonf-5.pdf (date of access: 11.02.2018)

8. D. Cave, The Interpreter (2015) URL: https://www.lowyinstitute.org/the-interpreter/doesaustralia-do-digital-diplomacy (date of access: 02.04.2018) 
9. O.S. Adesina, J. Summers, Cogent Social Sciences 3 (2017)

10. L. Permyakova, Digital diplomacy: directions, risks and tools (2012) URL: http://russiancouncil.ru/analytics-andcomments/analytics/tsifrovaya-diplomatiyanapravleniya-raboty-riski-i-instrumen/ (date of access: 15.02.2018)

11. N. Westcott, Research Report Oxford Internet Institute 16, 20 (2008)

12. Preparing for peace. Communications in conflict resolution (OSCE Publishing, Vienna, 2012) URL: http://www.osce.org/networks/98116?download=tru e (date of access: 14.11.2017)

13. N. Bryant, BBC News Magazine (2012). URL: http://www.bbc.com/news/magazine-18856295 (date of access: 04.04.2018)

14. AFP launches "the e-diplomacy hub", an innovative tool for exploring the world of digital diplomacy. Newsletter (2012) URL: https://www.afp.com/en/agency/press-releasesnewsletter/afp-launches-e-diplomacy-hubinnovative-tool-exploring-world-digital-diplomacy (date of access: 18.02.2018)

15. M. Lüfkens. Twiplomacy 2017 - Full Study URL: https://www.burson-marsteller.com/what-wedo/our-thinking/twiplomacy-2017/twiplomacy2017-full-study/ (date of access: 19.02.2018)

16. O.S. Adesina, J. Summers, Cogent Social Sciences 3 (2017)

17. C. Bjola, Trends and counter-trends in digital diplomacy (2017) URL: https://medium.com/digitaldiplomacy/trends-and-counter-trends-in-digital-

diplomacy-f1f2c1625f26 (date of access: 20.07.2017) 